\title{
HiRES airborne geophysical surveys in the UK: the Anglesey magnetic perspective
}

\author{
David Beamish ${ }^{*}$ and Jim White \\ British Geological Survey, Keyworth, Nottingham, NG12 5GG, UK.
}

Beamish, D. \& White, J., 2010. HiRES airborne geophysical surveys in the UK: the Anglesey magnetic perspective. $72^{\text {nd }}$ EAGE Conference \& Exhibition, Barcelona, Spain, June 2010. Extended Abstract W2-02.

DOI : $10.3997 / 2214-4609.20149911$

\section{SUMMARY}

This paper provides a comparison of vintage, UK national scale aeromagnetic data and modern, high resolution airborne data using a case study across the island of Anglesey, NW Wales. Deeper responses associated with magnetic basement are masked by a near-surface Palaeogene dyke swarm. In order to extract shallow and deeper basement features both data sets are processed in a consistent manner using azimuthal and spectral filtering procedures. A joint assessment is then carried out on the resolution capabilities of both data sets using established edge and depth location methodologies.

\section{Introduction}

A number of modern, multi-parameter geophysical surveys (termed HiRES) have been conducted over the past decade across onshore UK. These were undertaken, in part, as a response to the limited resolution of the existing UK national magnetic survey data set acquired in the late 1950's and early 1960's. It is self-evident that the modern surveys provide improved resolution; our purpose here is to quantify the improvements that can be anticipated using the new data. The framework for the study involves two components. The first relates to the definition of shallow magnetic structure in relation to ongoing $1: 10 \mathrm{k}$ and $1: 50 \mathrm{k}$ geological map revision. The second component relates to the performance of the datasets in defining maps of magnetic basement. One of the smaller HiRES survey areas, the island of Anglesey (Ynys Môn), off the coast of NW Wales is used to provide a series of comparative studies. The geological setting here is both complex and controversial. A wide number of near-surface magnetic features are evident and are dominated by a reversely magnetized Palaeogene dyke swarm extending offshore. In order to define and refine location/depth information from the complete magnetic spectra of both the existing and new datasets, a series of equivalent azimuthal and spectral filtering procedures have been performed prior to structural assessment using established edge and depth location methodologies.

\section{Data Sets}

The existing UK national magnetic data set is that described on the 1:1.5M magnetic map compilation (BGS, 1998). Over the $110 \mathrm{x} 135 \mathrm{~km}$ onshore/offshore study area considered here, line spacing varies between 2 and $4 \mathrm{~km}$ and nominal survey elevation is $305 \mathrm{~m}$. Gridding at the maximum grid resolution of 500 x $500 \mathrm{~m}$ requires some interpolation across undersampled localities. The TMI RTP anomaly field is shown in Figure 1 in relation to the outline of the modern HiRES survey centred on the island of Anglesey. The largest amplitudes are observed in association with the volcanic Snowdon Massif in the SE. Elsewhere, magnetic high values associated with longer wavelengths display a NE-SW orientation. These are features that we would associate with magnetic basement. Even with no processing applied to these data; a series of higher wavenumber linear features can be traced crossing 
the area with a NW-SE trend. These features are a set of Palaeogene dykes that have been previously discussed, in terms of their geophysical responses, by Bevins et al. (1996). The corresponding TMI RTP anomaly HiRES data acquired in 2009 using $200 \mathrm{~m} \mathrm{~N}-\mathrm{S}$ lines and at a nominal elevation of $56 \mathrm{~m}$ are shown in Figure 2. HiRES TMI survey data are sampled every 3-5 $\mathrm{m}$ and are routinely gridded at $50 \mathrm{~m}$ intervals. An initial comparison of the two data sets reveals the persistence of longer wavelength features trending NE-SW. This direction is that of the three dominant tectonic terranes on the island that make up the crustal units associated with Precambrian (Avalonian) subduction (Gibbons and Horák, 1990). Features noted in Figure 2 are a reversely magnetised main dyke intrusion (1), the response of ultrabasic serpentanite (2) and a newly resolved offshore feature (3). Positive magnetic lineaments lie in hanging wall of the Carmel Head Thrust (CH). The Berw fault (B) marks the NW limit of a shear zone associated with a belt of blueschists that are interpreted as a small piece of the accretionary orogen.

\section{Processing}

Comparisons of the spectral content of the two gridded data sets reveal the greater energy content of the HiRES data particularly across the wavelength interval from 1 to $10 \mathrm{~km}$. Only the HiRES data provide information in the interval from $100 \mathrm{~m}$ to $1 \mathrm{~km}$. It is evident from the data presented that shallow and deeper magnetic sources are directionally distinct and are close to being orthogonal. This directional dependence is exploited in the structural assessments considered below.

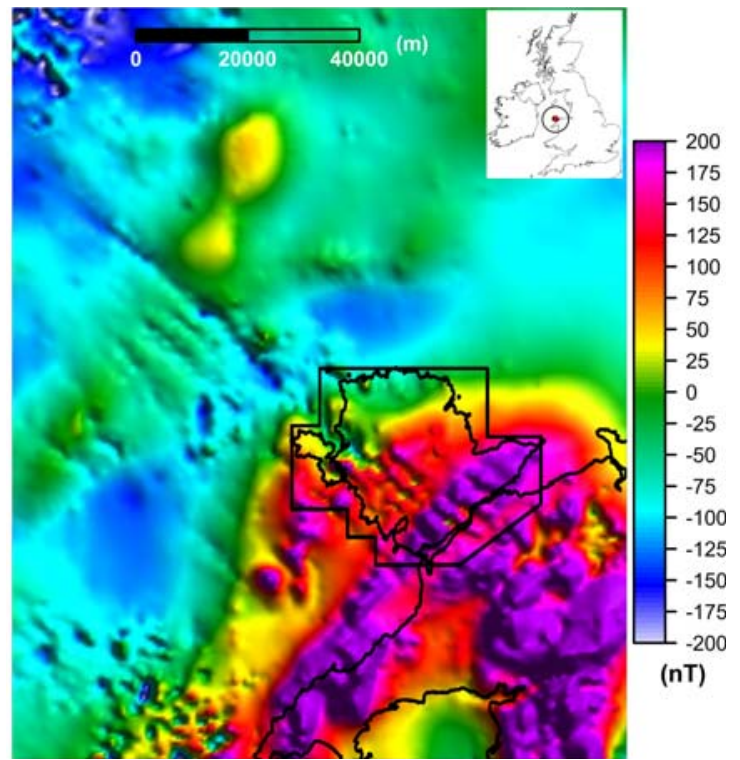

Figure 1. TMI RTP anomaly of vintage data covering offshore/onshore Anglesey. Polygon denotes recent HiRES survey area. Linear colour scale. Shading from NE.

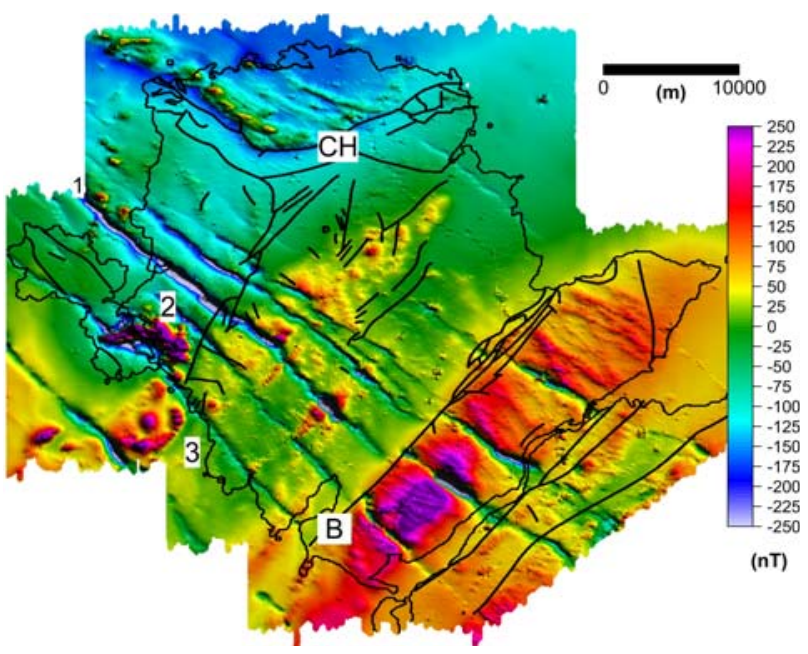

Figure 2. TMI RTP anomaly map of recent HiRES survey. Black lines denote coast and 1:250k geological faults. CH: Carmel Head Thrust, B: Berw Fault, 1: largest amplitude dyke extending offshore, 2: Ultrabasics, 3: new structure, just offshore. Linear colour scale, shading from NE.

Azimuthal (directional) filters have been applied in the wavenumber domain to selectively remove signal and noise along specified directions. To avoid introducing artefacts we use a smooth cosine function of degree 2 having a gain of unity at the chosen azimuth and a gain of zero in the orthogonal direction. Structural information in the data sets is examined using the Tilt Derivative (TDR) as described by Millar and Singh (1994). The function typically allows a normalisation of both shallow and deep sources in broadband TMI anomaly data but here we also apply it to anomaly data that have been subjected to matched spectral filtering. This procedure has been used to estimate layered models 
of magnetisation including a terminating half-space which we equate to magnetic basement. We note that previous descriptions of TDR applications only involve cases of positive (meaning vertically downward) magnetic inclinations. Here, in the shallow analysis, both normal and reverse magnetisation directions are encountered. Finally the location and depth of structural elements assessed using the TDR response of the processed data is compared with equivalent information from located Euler solutions (Reid et al., 1990).

\section{Shallow magnetic structure}

Shallow magnetic responses in both data sets are dominated by the largely concealed NW-SE Palaeogene dyke swarm. A directional cosine filter with a unity gain at $+135^{\circ}$ was applied to both data sets. The TDR response of these data was then calculated. A comparison of the TDR response data in the vicinity of the HiRES survey is shown in Figure 3. We isolate the reversely magnetised features of dykes by showing contours of the TDR interval from -45 to -90 which theoretically outline the centres of source locations. Grey contours are used for existing data and blue contour zones define the HiRES results. In broad terms the existing data detect the main (large amplitude) structures traversing the survey area. When compared to the HiRES results, the resolution of existing data is poor and dyke centres may be mislocated by $>1 \mathrm{~km}$. The HiRES results show a greater degree of high wavenumber noise (cultural) artefacts. In the context of mapping quasi-continuous structures, their effects are not too severe. The new data also reveal a number of new potential concealed dyke structures, largely crossing the NE quadrant of the area. Contour features observed in association with

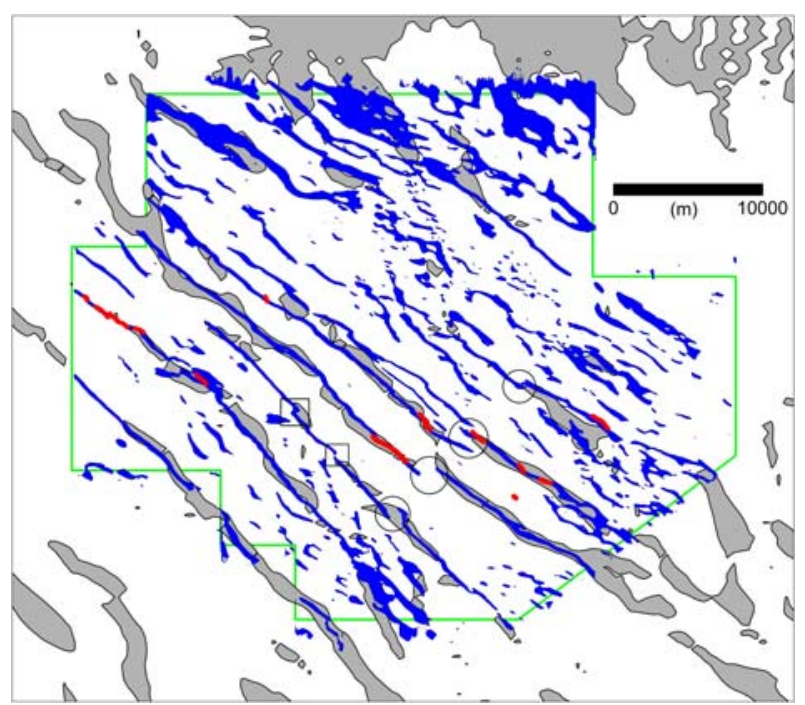

Figure 3. TDR response contours for interval $-45^{\circ}$ to $-90^{\circ}$. Grey: vintage data. Blue: HiRES. Red: mapped dykes. Dyke offsets are noted with open symbols. and to the north of the northern thrust zone should be disregarded in the context of Palaeogene dyke assessments. As a form of control, the limited mapping of outcropping dykes is shown for reference. Located Euler solutions (not shown here) have also been applied to the rotated data sets. The location of accurate ( $<10 \%$ threshold) solutions largely trace the dyke centres shown in Figure 3. The solutions provide a depth distribution (below surface) with a median depth of $53 \mathrm{~m}$ and with first and third quartiles at depths of 30 and $83 \mathrm{~m}$, respectively.

\section{Magnetic basement}

As noted above, significant differences exist in the spectral content of existing and new data sets at longer wavelengths. Both have relevance to the identification of the tectonic terranes of the study area. A matched filter spectral analysis of the unrotated existing magnetic anomaly data indicated a magnetic basement depth of about $13 \mathrm{~km}$. The magnetic basement half-space recovered by the procedure was again studied using the TDR response together with Euler solutions. The main deep body edge contact (10 to $12 \mathrm{~km}$ ) traverses onshore Anglesey in the NW and is described elsewhere. 


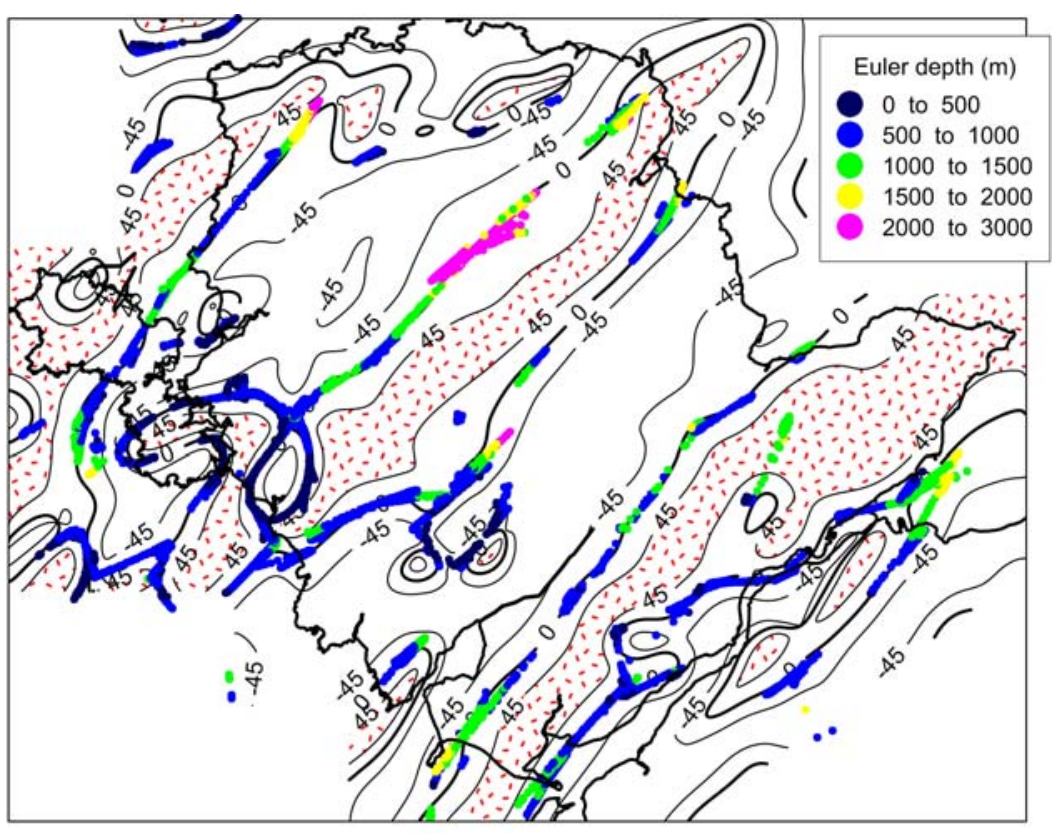

Figure 4. Shallow magnetic basement. TDR response (black contours at $45^{\circ}$ intervals and stippled $45^{\circ}$ to $90^{\circ}$ ) and located Euler solutions (symbols).
Matched filter analysis of the HiRES data set was conducted on directionally filtered data (unity pass at $+45^{\circ}$ ) due to the interference generated by the dyke swarm. The analysis indicated 3 magnetic layers above a halfspace at a depth of $2650 \mathrm{~m}$ below ground surface. Again the basement information was studied using a combination of TDR and Euler solution

procedures. The results are summarised in Figure 4. Assuming normal positive magnetisation contrasts, the TDR response outlines 3 bodies across the contour interval from $-45^{\circ}$ to $+45^{\circ}$. The centres of the bodies (TDR interval $45^{\circ}$ to $90^{\circ}$ ) are shown stippled for clarity. The full resolution of all 3 zones is limited by the survey extent. The Euler solutions provide a close tracking of the zero contour of the TDR response (assumed to be an edge locator). In addition, the approximate depth to contact estimate provided by the TDR distance interval $\left(-45^{\circ}\right.$ to $\left.+45^{\circ}\right)$ follows the variation in depth estimates of the Euler solutions. The joint appraisal of source edge location and depth provides increased confidence in the interpretation.

The 3 principal magnetic bodies are contained within 3 distinct terranes of the Monian Composite Terrane (Gibbons and Horák, 1990). The contact margin in the NW is perhaps the most intriguing since it appears to dip to depths in excess of $2 \mathrm{~km}$ and to terminate in the hanging wall of the Carmel Head Thrust. The central body shows a close association with a central granite body (the Coedana Granite) and related shear zones while the body in the SE partially tracks a blueschist outcrop and the Berw Fault, but not identically.

\section{Conclusions}

The study has considered existing national scale UK magnetic data across Anglesey in relation to one of a number of modern high resolution data sets. Inevitably the vintage data is limited in resolving features $<1 \mathrm{~km}$ in scale however the comparisons reveal that a broad assessment of linear shallow features (e.g. dykes largely confined to the upper $100 \mathrm{~m}$ ) can be achieved. The precise limitations are revealed when the HiRES data are used in a joint assessment. Both the locations, widths and presence of lower amplitude features, including offsets, may be either misrepresented or omitted by the vintage data. The resolution capabilities regarding basement features of the 2 data sets are related to spectral content. The strength of the vintage data lies in the assessment of deep (e.g. $>10 \mathrm{~km}$ ) magnetic basement features that, in this case study, cannot be achieved by the new data. Conversely, the vintage data provide no discrimination of shallow (e.g. $<3 \mathrm{~km}$ ) basement features. These features are highly resolved in the new data and are, in fact, of critical significance in establishing concealed basement structures associated with distinct, but disputed, terranes that may have been accreted during Avalonian subduction. 


\section{Acknowledgement}

This paper is published with the permission of the Executive Director, British Geological Survey (NERC).

\section{References}

British Geological Survey, [1998] Colour Shaded Relief Magnetic Anomaly Map of Britain, Ireland and adjacent areas. Royles, C P and Smith, I. F. (compilers) 1:1 500000 scale (Keyworth, Nottingham, UK).

Bevins, R.E., Horák, J.M., Evans, A.D. and Morgan, R. [1996] Palaeogene dyke swarm, NW Wales: evidence for Cenozoic sinistral fault movement. Journal of the Geological Society of London, 153, 177-180.

Gibbons, W. and Horák, J.M. [1990] Contrasting metamorphic terranes in northwest Wales. In: D'Lemos, R.S., Strachan, R.A. and Topley, C.G. (Eds.) The Cadomian Orogeny. Geological Society, London, Special Publications, 51, 315-328.

Miller, H. G. and Singh, V. [1994] Potential field tilt - A new concept for location of potential field sources. Journal of Applied Geophysics, 32, 213-217.

Reid, A.B., Allsop, J.M., Granser, H., Millet, A.J., and Somerton, I.W. [1990] Magnetic interpretation in three dimensions using Euler deconvolution. Geophysics, 55, 80-91. 